IZA DP No. 6225

Gender Differences in Rates of Job Dismissal: Why Are Men More Likely to Lose Their Jobs?

Roger Wilkins

Mark Wooden

December 2011 


\title{
Gender Differences in Rates of Job Dismissal: Why Are Men More Likely to Lose Their Jobs?
}

\author{
Roger Wilkins \\ MIAESR, University of Melbourne \\ Mark Wooden \\ MIAESR, University of Melbourne \\ and IZA
}

Discussion Paper No. 6225

December 2011

IZA

P.O. Box 7240

53072 Bonn

Germany

Phone: +49-228-3894-0

Fax: +49-228-3894-180

E-mail: iza@iza.org

Any opinions expressed here are those of the author(s) and not those of IZA. Research published in this series may include views on policy, but the institute itself takes no institutional policy positions.

The Institute for the Study of Labor (IZA) in Bonn is a local and virtual international research center and a place of communication between science, politics and business. IZA is an independent nonprofit organization supported by Deutsche Post Foundation. The center is associated with the University of Bonn and offers a stimulating research environment through its international network, workshops and conferences, data service, project support, research visits and doctoral program. IZA engages in (i) original and internationally competitive research in all fields of labor economics, (ii) development of policy concepts, and (iii) dissemination of research results and concepts to the interested public.

IZA Discussion Papers often represent preliminary work and are circulated to encourage discussion. Citation of such a paper should account for its provisional character. A revised version may be available directly from the author. 


\section{ABSTRACT}

\section{Gender Differences in Rates of Job Dismissal: Why Are Men More Likely to Lose Their Jobs?*}

Empirical studies have consistently reported that rates of involuntary job separation, or dismissal, are significantly lower among female employees than among males. Only rarely, however, have the reasons for this differential been the subject of detailed investigation. In this paper, household panel survey data from Australia are used that also find higher dismissal rates among men than among women. This differential, however, largely disappears once controls for industry and occupation are included. These findings suggest that the observed gender differential primarily reflects systematic differences in the types of jobs into which men and women select.

JEL Classification: J16, J63, J71

Keywords: dismissals, gender differentials, involuntary job separations, HILDA Survey, Australia

Corresponding author:

Mark Wooden

Melbourne Institute of Applied Economic and Social Research

The University of Melbourne

Victoria 3010

Australia

E-mail: m.wooden@unimelb.edu.au

\footnotetext{
* This paper uses unit record data from the Household, Income and Labour Dynamics in Australia (HILDA) Survey, a project initiated and funded by the Australian Government Department of Families, Housing, Community Services and Indigenous Affairs (FaHCSIA) and managed by the Melbourne Institute of Applied Economic and Social Research. The findings and views reported in this paper, however, are those of the authors and should not be attributed to either FaHCSIA or the Melbourne Institute.
} 


\section{Introduction}

Gender differences in labor mobility, both within and across firms, have been the subject of considerable research. There is also a much larger body of research concerned with gender differences in labor market behavior and outcomes. Much of this literature has focused on earnings, although labor force participation, unemployment, hiring and promotion have also been examined. One topic that has received relatively little attention from either research strand is gender differences in involuntary job loss. This is potentially an important dimension for understanding differences between men and women in their labor market behavior and experiences. In particular, a consistent empirical regularity, observed in data from many countries, is that men have a substantially higher rate of dismissal from employment than women. The question that most obviously follows from this observation is whether it represents a compensating differential that helps to explain the well known gender pay gap. That is, could it be that women tend to choose jobs with lower wages that are, at least in part, compensated by lower layoff risks? Or does the lower dismissal rate reflect other factors, such as differences in the characteristics of male and female employees, or indeed employer discrimination in favour of women?

In this paper, we draw on data from the Household, Income and Labour Dynamics in Australia (HILDA) Survey collected over the 2001-2009 period to examine alternative potential explanations. In common with findings of studies drawing on other data sources, these data show that men have a considerably higher rate of job loss, with the proportion of employees dismissed or made redundant each year approximately $45 \%$ higher for male employees than for female employees. We hypothesize that the higher rate of involuntary job loss among men could be the result of differences between men and women in the characteristics of those who choose to participate in the labor market, differences in job choices and/or differences in employer treatment of observationally similar men and women. 
We investigate the issue by estimating random effects probit models of the probability of job loss during the next year as a function of a wide range of demographic and job-related characteristics. Compared with previous studies, we are able to control for a much broader array of factors, including personal characteristics such as personality, and employment-related characteristics such as detailed occupation and industry category. Ours is also one of the few studies to relax the pooling restriction, allowing effects of demographic and job characteristics to differ for men and women thus facilitating the decomposition of the sources of the gender difference in the dismissal rate. Estimates we obtain indicate that the higher rate of job loss for men has little to do with differences in observable characteristics of men and women and, consistent with the compensating differential hypothesis, is largely explained by differences in the types of jobs men and women have. In particular, differences in the industry and occupation composition of male and female employment account for much of the difference in dismissal rates.

\section{Previous Research}

The seminal work on the relationship between involuntary separations and gender is that of Blau and Kahn (1981). They used data from the 1966 and 1968 cohorts of the National Longitudinal Survey (persons in the US aged between 14 and 24) to estimate probit models of the probability of permanent layoff disaggregated by both sex and race. They found that the unadjusted rate of layoff for males was close to double that of females. Further, this gap actually increased once other personal and labor market characteristics were controlled for.

Until recently, this finding largely went unchallenged, with most research that has touched on this issue, usually only in passing, also reporting evidence that women are much less susceptible to involuntary separations than are men. Included here are: studies of workers from single firms (Barrick, Mount and Strauss 1994; Giulano, Levine and Leonard 2006; Stumpf and Dawley 1981; Wells and Muchinsky 1985); studies of non-representative samples of workers but employed across 
many firms (Campbell 1997; Theodossiou 2002); studies employing representative population-based samples, including in Australia (McGuinness and Wooden 2009), Brazil (Orellano and Picchetti 2005), Canada (Picot, Lin and Pyper 1998), the UK (Booth, Francesconi and Garcia-Serrano 1999), and the US (Freeman 1980; Keith and McWilliams 1999); and studies using firm-level data (Antcliff and Saundry 2009; Balchin and Wooden 1995).

A very different result, however, was reported by Booth and Francesconi (2000). Using longitudinal data from the British Household Panel Survey covering the period 1991 to 1996, they reported evidence that female employees were significantly more likely to be laid off than men (a $7 \%$ annual layoff rate for women compared with $6.3 \%$ for men), and that this differential was not much affected by the inclusion of controls for individual and job characteristics. This finding is especially surprising given the authors' earlier work drawing on the same data source (Booth, Francesconi and Garcia-Serrano 1999), but admittedly using retrospective work history data collected at one point in time rather than prospective longitudinal data, obtained conclusions that were entirely consistent with the original finding of Blau and Kahn (1981). The sample used by Booth and Francesconi (2000) in obtaining their results, however, was unusual in that it both restricted the sample to persons in full-time employment, thus excluding many female employees, and much more importantly, excluded all job to non-employment transitions. In other words, the only cases of involuntary separation that were retained were those where the laid-off worker had secured alternative employment by the time of the next survey interview. The restriction to full-time workers was defended on the (quite reasonable) grounds that the authors were only interested in the behaviors of workers with a strong attachment to the labor market. In contrast, no rationale for the exclusion of job to non-employment transitions was provided, and in our view this exclusion is difficult to defend - it almost certainly introduces a serious form of selection bias.

More challenging are the results reported by Goerke and Pannenberg (2010). Following Blau and Kahn (1981), they estimated probit models of dismissals, but using longitudinal data for West Germany that spanned a period of 20 years commencing in 1985 (though they were only able to use 
data from six time points within that period). The key feature of their analysis was the exploitation of the panel nature of the data in an attempt to better deal with time-invariant individual unobserved heterogeneity. This is potentially of large importance given the very limited number of control variables included in previous research. Like Booth and Francesconi (2000) they restricted the sample, but only to private sector, prime-age, full-time workers. Further, and like much of the research in this space, their focus was not on gender per se; rather it was on the effects of trade unions (cf. Freeman 1980). Nevertheless, they included a gender dummy and were unable to find any evidence that male employees are more susceptible to dismissal than females. Indeed, in a pooled data model female employees were found to be significantly more likely to be dismissed from their jobs than were male employees. This effect, however, declined in size and became statistically insignificant once correlated random effects were allowed for.

Such findings suggest that the conventional wisdom that female employees are less likely to be dismissed or laid off by their employers than male employees either may not hold in all institutional settings, or that the relationship between involuntary separations and gender may be changing over time. This, in turn, suggests the need for new research using more recent data and conducted outside the US (and the UK). There is also a clear need for research with a more explicit focus on gender. It is not sufficient just to know the magnitude of any gender gap in separation rates and whether that gap is affected by the inclusion of controls. As in studies of the gender pay gap, it is also important to know how the separation rates of men and women are affected by different covariates. We, however, are only aware of a handful of studies that allow the covariates of involuntary separations to vary with gender (Blau and Kahn 1981; Booth, Francesconi and GarciaSerrano 1999; Booth and Francesoni 2000; Theodossiou 2002).

Of particular interest is the role of industry and occupation. It is widely recognized that occupational and industrial segregation continues to plays an important role in contributing to the gender pay gap in most industrial nations (e.g., Altonji and Blank 1999). Is it not, therefore, possible that this same segregation might also explain observable differences in involuntary separations? 
That is, women may select into industries and occupations where the risk of involuntary separation is relatively low. Previous research on gender differences in involuntary separation, however, have not given this issue serious attention, being content to control for the effects of industry and occupation segmentation through the inclusion of a small number of dummy variables.

\section{Data and descriptive statistics}

Discussed in more detail in Wooden and Watson (2007) and Watson and Wooden (2010), the HILDA Survey is a household panel survey that began in 2001 with a large nationally representative sample of Australian household members occupying private dwellings. In wave 1 , interviews were completed with 13,969 people aged 15 years and over in 7682 households. All members of responding households from wave $1(n=19,194)$ form the basis of the panel to be followed over time, though interviews are only conducted with those household members aged 15 years or older. Interviews are conducted every year. While the survey has a longitudinal design, it employs following rules that, with one caveat, are designed to ensure the sample maintains its cross-sectional representativeness over time. This is achieved by adding other people who join households in which original sample members reside. Most important here are children of original sample members. The one obvious weakness in the sample generation process is that immigrants who arrive in Australia after the initial sample was selected have relatively little chance of being included.

Information on dismissal from employment is obtained in every survey wave (since wave 2), by asking survey respondents who have changed employers or ceased working since the last interview for both the main reason they stopped working in the main job held at the time of last interview and. Responses are then coded against a set of pre-coded categories, one of which is: 'Got laid off / No work available / Retrenched / Made redundant / Employer went out of business / Dismissed etc.' This response option thus covers a number of scenarios, but all involve termination of employment that is not initiated by the employee. ${ }^{1}$ The reference period is from the date of last interview to the 
date of current interview, which given the annual interviewing cycle will typically be around one year. There is, however, considerable variation around this; most notably in those cases where a respondent did not respond in one or more of the preceding waves. We have, therefore, excluded from all analyses reported in this paper any observations where a respondent was not interviewed in the wave immediately preceding the current wave. This ensures a more determinate time-frame for reports of dismissals. In addition, we exclude the self-employed and employers, since the concept of job dismissal we seek to investigate applies only to employees.

Figure 1 presents estimates of dismissal rates for the definition and population that are the focus of this study. Specifically, for each wave, it presents the proportion of employees dismissed from their main job by the time of interview at the next survey wave. Approximately 5.3 per cent of males who were employees in wave 1 (i.e., 2001) were dismissed from their main job at some stage prior to being interviewed in wave 2. This dismissal rate fell to as low as 3.1 per cent for the year following wave 7, before increasing sharply to 6.7 per cent for the wave 8 to wave 9 interval (reflecting the impact of the global financial crisis on the Australian labor market). For females, the corresponding dismissal rate fell from 4.1 per cent in wave 1 to 2.8 per cent in wave 7 , before increasing to 5.6 per cent in wave 8 .

Table 1 compares average annual dismissal rates for men and women over the 2001 to 2009 period disaggregated by age, full-time/part-time status, type of employment contract, firm size and sector. The average difference between men and women in the annual rate of dismissal over the HILDA Survey sample period is approximately 1.3 percentage points. While not a large gap in absolute terms, the quite low probability of dismissal in any given year (irrespective of sex) means that this translates to a 46 per cent higher probability of dismissal for males.

Disaggregation by age and by employment characteristics indicates that the male-female differential is not confined to a narrow group of employees. While there are significant variations in dismissal rates by age, employment status, type of employment contract, firm size and sector, the 
male-female gap is at least 1.1 percentage points for all groups, and as large as two percentage points in the case of casual employees. This would seem to provide some tentative evidence that the gap is not likely to be attributable to differences in either the composition of male and female employment or in the types of jobs in which men and women are employed. Of course, Table 1 only considers differences in dismissal rates across a small number of personal and job characteristics; most notably, differences by occupation and industry are not reported.

\section{Conceptual framework}

The differences in the dismissal rates between male and female employees evident in the HILDA Survey data, and found in data for other countries, lead to the obvious question of why they exist. Potential reasons for the differential can be classified as falling into one of three broad classes of explanation: (1) differences in the characteristics of male and female employees; (2) differences in the job choices of male and female labor market participants; and (3) differences in employer behavior towards similar male and female employees.

The first hypothesized reason could involve females who are relatively likely to be dismissed (e.g., those with low skills or poor health) being less likely to participate in the labor market than similar males. It could also involve females more generally tending to have characteristics, such as personality traits, that translate into behavior making dismissal less likely. For example, women may tend to be more conscientious than men. While these types of factors have been implicitly considered in the studies that control for personal characteristics, such as Blau and Kahn (1981), Booth et al. (1999), Booth and Francesconi (2000) and Theodossiou (2002), no previous study has explicitly controlled for personality. Factors commonly considered include age, educational attainment, work experience and ethnicity or race. Characteristics such as these may matter because they translate to differences in job performance and other behavior in employment, and because 
they may be associated with differences in employer behavior (e.g., employers may be more prepared to fire young workers).

Some of the differences between men and women will be difficult to observe. One interpretation of such 'unobservable' differences is that men and women are 'inherently different', and therefore perform or behave differently even when they have the same observable characteristics. The higher rate of dismissal among men may thus imply that men are more likely to shirk, underperform or engage in other behaviors provoking dismissal than are women of the same age, health, educational attainment, and so on. Balchin and Wooden (1995) suggest this as an explanation for their finding that the rate of dismissal was decreasing in the proportion of a firm's workforce that is female, hypothesising that female workforces are more compliant.

The second potential explanation, differences in job choices, would involve women tending to choose jobs with lower risks of dismissal (e.g., jobs in the public sector). Women may be more averse to jobs with greater dismissal risks because of differences in the expected costs and benefits of jobs with greater dismissal probabilities. For example, costs of dismissal may be higher for women if they are more constrained in the distance they can travel to work due to family responsibilities. Women may also have different preferences, including attitudes to risk, leading to greater preference for jobs with less risk of dismissal. Indeed, numerous studies have found a gender pay gap favouring men, which could in theory reflect compensation for non-wage attributes, such as a lesser degree of hours flexibility, greater travel to work times, greater health and safety risks and, of course, less job security.

Potentially relevant employment-related characteristics most obviously include occupation, industry and sector, since there are likely to be systematic differences across occupations, industries and sectors in rates of dismissal, reflecting the varying nature of demand conditions faced by employers. Other potentially important factors include the type of employment contract, the number of hours worked, the timing of work hours, firm size, the length of the employee's job 
tenure, and the employee's wage rate. Ex ante, one would expect job dismissal to be less prevalent among permanent or ongoing staff, among full-time workers, and in larger firms. Blau and Kahn (1981) further postulate that, all else equal, the higher the wage, the greater the probability of dismissal. With regards to job tenure, they suggest it may be negatively associated with dismissal because those with longer tenure are likely to have higher levels of firm-specific human capital, which is a source of joint surplus from the employment relationship. ${ }^{2}$ Blau and Kahn also argue that dismissal probabilities are increasing in the 'replaceability' of the employees, which might suggest that working irregular hours and at non-standard times of the day and week reduces the likelihood of dismissal given it is harder to find workers prepared to work those hours. While not a job characteristic per se, the local unemployment rate may also provide an indication of the replaceability of employees and the employer's demand conditions, and thus would be expected to be positively associated with the dismissal rate.

The third potential explanation, differences in employer propensity to dismiss men and women, could arise from factors such as societal norms and fears of being accused of discrimination. This potential source of difference in dismissal rates is difficult to separately identify from the effects of differences in unobservable characteristics, since it is observationally indistinguishable without direct information on employee job performance. However, having rich information on employees' characteristics reduces the scope for unobserved characteristics to be responsible for differences between men and women in dismissal rates. If we also have a sufficiently rich set of covariates for employment-related characteristics, it is likely that employer behaviour is the source of any difference in the dismissal rate that remains once personal and employment-related characteristics are controlled for. The HILDA Survey collects considerable information about both personal and employment related characteristics, so that a finding of such a 'residual' difference in the dismissal rate could quite reasonably be attributed to employer discrimination against males. 


\section{Models of the determinants of dismissal}

Methods. We estimate probit models of the probability of dismissal of employees, taking advantage of the panel structure of the data to control for unobserved individual heterogeneity by adopting a random effects specification. An individual contributes an observation for each wave in which he is an employee, provided he is also a respondent in the next wave. Given nine waves of data, an individual can therefore contribute up to eight observations. The outcome variable is a dummy indicator equal to one in the current wave if the employee reports in the next wave that he or she was dismissed from the main job held in the current wave. All characteristics are evaluated in the current wave (rather than the wave in which dismissal was reported) to allow job characteristics to be tied to the job from which the employee was dismissed.

Reflecting the potential factors canvassed earlier, a wide variety of explanatory variables is included in the models. ${ }^{3}$ We distinguish personal characteristics from job or employment characteristics on the basis that they conceptually capture distinct sources of differences in dismissal rates between men and women. We do this by estimating models with personal characteristics only, and then estimating models which also include job characteristics. When controlling for personal characteristics only, the estimate on the male dummy provides a measure of the difference in the dismissal probability that is not explained by differences in the characteristics of labor market participants. Controlling for both personal and job characteristics, the estimate on the male dummy provides a measure of the difference in the dismissal probability that is not explained by either the characteristics of labor market participants or the types of jobs they have.

Personal characteristics are captured by variables for age, educational attainment, work experience, health, disability, indigenous status and place of birth, personality, and household income. Work experience is equal to the number of years in employment since leaving full-time education for the first time. The health variable is the SF-36 measure of general health (Ware et al. 2000), which rates the respondent's health on a 0 to 100 scale based on responses to five subjective 
health-related questions, and is administered as part of a self-completion paper questionnaire (SCQ) that all respondents are asked to complete. Disability is captured by a dummy indicator for the presence of a long-term health condition, impairment or disability that restricts the respondent in everyday activities, and has lasted or is likely to last, for six months or more. For place of birth we distinguish between persons born in Australia and those born overseas, and among the latter between those born in the main English-speaking countries (or English-speaking-background [ESB] immigrants) and those born in other countries (or non-English-speaking-background [NESB] immigrants). The income variable is equivalized real disposable income of the household, where the equivalence scale used is the modified OECD scale (Haagenars, de Vos and Zaidi 1994).

Significantly, in waves 5 and 9, the SCQ contained a multi-item question designed to provide measures of the 'big five' personality traits - extroversion, agreeableness, conscientiousness, emotional stability and openness. The approach used to measure these traits is closely based on that used by Saucier (1994), and is described in more detail in Summerfield (2010). For this analysis, we assume personality is stable over the survey period ${ }^{4}$ and set values for each of the five traits at the mean score across the two waves in which the questions were administered.

Job or employment-related characteristics comprise variables for occupation, industry, sector (public or private), firm size (fewer than 20 employees, 20 to 99 employees, 100 or more employees), length of job tenure, type of employment contract (permanent / ongoing, fixed-term or casual), hours of work (part-time or full-time), timing of work hours (whether works weekends, nights or irregular hours) and the employee's wage (log real hourly wage).

Two alternative specifications are estimated, one with broad occupation and industry categories and the other with more disaggregated occupation and industry categories. ${ }^{5}$ Previous studies have only considered selection into occupations and industries in a very limited way. Blau and Kahn (1981) included just one occupation dummy and one industry dummy, Booth and Francesconi (2000) included four occupation dummies and no industry dummies, Theodossiou 
(2002) included four industry dummies and no occupation dummies, and Booth et al. (2000) included nine industry dummies and six occupation dummies. We consider the potential role of selection into occupations and industries in considerably more depth. The aggregated specification contains eight occupation dummies and nine industry dummies, while the disaggregated specification contains 40 occupation dummies and 52 industry dummies.

Blau and Kahn (1981) also identify 'replaceability' of employees as a factor positively affecting the layoff probability, which they attempt to capture by inclusion of the local unemployment rate. We likewise include such a variable in our estimated models, although only disaggregated to the level of State capital city and balance of State. Also included in the models are wave dummies, which will capture macroeconomic conditions and other time-related macroeconomic factors.

Results. Table 2 presents 'mean marginal effects' estimates, obtained by evaluating the marginal effect of each variable on the probability of dismissal for each observation in the sample and taking the mean of these effects over all observations. Specification (i) shows a one percentage point higher predicted probability of dismissal for males after controlling for personal characteristics, which is slightly less than the raw empirical difference of 1.3 percentage points. As might be expected, degree-level educational qualifications and greater work experience are associated with lower probabilities of dismissal, while poorer health is associated with a higher risk of dismissal. Conscientiousness has a negative effect on the likelihood of dismissal, while extroversion and openness to experience have positive effects, although the estimate for openness to experience is only weakly significant. Point estimates furthermore show negative effects for agreeableness and emotional stability, but these are not statistically significant. Immigrant and indigenous employees have higher probabilities of dismissal, holding other personal characteristics constant, while no effect is evident for household income. Perhaps surprising is that no significant differences by age group are evident; however, employees with less than ten years of work experience are significantly more likely to be dismissed than more experienced employees, implying it is work experience, rather than age per se, that matters for the likelihood of dismissal. 
Adding job-related characteristics with aggregated industry and occupation groupings (specification (ii)) reduces the gender gap in predicted probability of dismissal to 0.5 percentage points. This gap reduces further to a statistically insignificant 0.3 percentage points when the more disaggregated industry and occupation groupings are used. It would, therefore, seem that much of the gender gap is explicable by differences in the types of jobs chosen by men and women. As we might expect, the estimates for the industry and occupation dummies in specification (ii) show relatively high rates of dismissal in manufacturing and construction industries and relatively low rates in government, education and health industries and in professional occupations. Also as expected, employees in the public sector are much less susceptible to dismissal than their private sector counterparts. In terms of other job characteristics, all else equal, the probability of dismissal is higher for casual jobs, employees of small firms, and more highly paid employees, and lower for employees with longer job tenure (up to approximately 37 years, based on the estimates for tenure and tenure squared) and employees working nights or irregular hours. All of these findings are consistent with our a priori expectations. Contrary to expectations, however, there is no evidence of a positive association with the local unemployment rate (though this possibly reflects the coarseness of the measure used).

Sensitivity Tests. We examine the robustness of the findings presented in Table 2 by conducting several sensitivity tests, results of which are presented in Table 3. Tests are conducted on each of the three specifications reported in Table 2, with the mean marginal effects estimates for the male dummy presented in Table $3 .^{6}$

The first sensitivity test adopts a broader definition of dismissal, redefining the term to also include employees who left their main job because it was temporary or seasonal. The second variation reported in Table 3 is motivated by the approaches taken by both Booth and Francesconi (2000) and Goerke and Pannenberg (2010), and restricts the sample to employees with a 'strong' attachment to the labor market, defined as those employed full-time and with at least two years work experience. Restricting to full-time employees with at least two years of work experience 
reduces the sample size by approximately 38 per cent. The third sensitivity test involves an alternative sample selection restriction: the exclusion of employees who voluntarily leave the job. Blau and Kahn (1981) employ this restriction, arguing that it is necessary given some quitters may have pre-empted imminent layoff. This restriction results in approximately 11 per cent of employees being excluded.

Since we are using panel survey data, there is the possibility that results are biased due to endogenous attrition. It might be expected, for example, that persons who change jobs might be more likely to discontinue survey participation. To test for attrition bias we use two variable addition tests, the results of which are reported on in the fourth and fifth sensitivity tests shown in Table 3. Following Verbeek and Nijman (1992), the fourth sensitivity test includes as a regressor a count of the number of waves the sample member was a respondent. This variable, which can take values ranging from two to nine, was not statistically significant in any of the three specifications, suggesting the absence of attrition bias. However, Verbeek and Nijman's approach implicitly assumes each sample member could have responded in every wave, which is not the case for the HILDA Survey, since panel members can be out of scope in some waves for reasons such as age (less than 15), migration and death. We therefore estimated an alternative model (the fifth sensitivity test reported in Table 3) which replaced the 'number of waves responded' variable with 'the proportion of in-scope waves in which the sample member responded'. This variable was statistically significant suggesting dismissal is correlated with panel attrition, though counter to a priori expectations the coefficient was positively signed, with mean marginal effect estimates of $0.044,0.050$ and 0.050 in the three respective specifications.

But despite this, the estimate on the gender differential is little affected. Indeed, the results presented in Table 3 reveal that the mean marginal effects estimates on the gender dummy are almost completely unaffected by any of the variations considered. Controlling for personal characteristics only, males have an approximately one percentage point higher probability of dismissal in all specifications. Adding job characteristics with aggregated occupation and industry 
groups reduces this to 0.5 percentage points, while detailed occupation and industry categories further reduces it to 0.3 percentage points.

We also present, in the final row of Table 3, results from a 'pooled' probit model, which treats each observation as independent of all others. This provides information on the implications for the results presented in Table 2 of allowing for correlated random effects, giving the relatively standard result of a slightly larger estimate in specification (i), but having no perceptible effect on the estimates in specifications (ii) and (iii). The pooled probit results are also presented because the decompositions presented in the next section are conducted on pooled probit models due to the absence of techniques for decomposing random effects models.

\section{Decompositions of the difference in dismissal rates}

Total Effect of Differences in Characteristics. The estimated models reported on in the preceding section constrain the effects of explanatory factors to be the same for males and females. In this section, we relax this constraint, thereby allowing us to decompose the sources of difference in the probability of dismissal into two broad categories: (1) effects of differences between males and females in their personal and job characteristics; and (2) (unexplained) differences in the effects associated with these characteristics, as captured by differences between men and women in the coefficient estimates on the explanatory variables in the probit models of dismissal rates.

To do this we adopt a modified version of the Blinder (1973)-Oaxaca (1973) decomposition that can be applied to probit models. Following Fairlie (1999), who applied the technique to racial gaps in self-employment, a probit equation can be decomposed as follows:

$$
\begin{aligned}
\overline{Y_{m}}-\overline{Y_{f}}= & {\left[1 / N_{m} \sum_{i=1}^{N_{m}} \Phi\left(x_{i, m}^{\prime} \hat{\beta}_{m}\right)-1 / N_{f} \sum_{i=1}^{N_{f}} \Phi\left(x_{i, f}^{\prime} \hat{\beta}_{m}\right)\right] } \\
& +\left[1 / N_{f} \sum_{i=1}^{N_{f}} \Phi\left(x_{i, f}^{\prime} \hat{\beta}_{m}\right)-1 / N_{f} \sum_{i=1}^{N_{f}} \Phi\left(x_{i, f}^{\prime} \hat{\beta}_{f}\right)\right]
\end{aligned}
$$


where $\overline{Y_{m}}$ and $\overline{Y_{f}}$ are the predicted probabilities of dismissal for males and females, respectively, $x_{i, m}$ and $x_{i, f}$ are vectors of characteristics, $\beta_{m}$ and $\beta_{f}$ are vectors of the estimated coefficients, $N_{m}$ and $N_{f}$ are the sample sizes and $\Phi$ is the standard normal cumulative distribution function.

The first component in square brackets is the difference in predicted dismissal rates of males and females attributable to differences in characteristics, applying the male coefficients. The second term is the residual (unexplained) difference due to differences in the estimated coefficients. This has the same form as the standard Blinder-Oaxaca decomposition applied to linear models, and has strong parallels with the mean marginal effects presented earlier. Specifically, rather than using the mean values of characteristics and decomposing the dismissal probability as $\left[\bar{x}_{m}^{\prime} \hat{\beta}_{m}-\bar{x}_{f}^{\prime} \hat{\beta}_{m}\right]+\left[\bar{x}_{f}^{\prime} \hat{\beta}_{m}-\bar{x}_{f}^{\prime} \hat{\beta}_{f}\right]$, the mean predicted probability is calculated for of each of the four terms, evaluated over all observations in the term. As in the linear case, decompositions can be evaluated using the male coefficients (as in equation (1)) or using the female coefficients, which will generally produce different, but equally valid, results. $^{7}$

We estimate the same three specifications reported on in Table 2, but models are estimated separately for males and females. Note we employ the pooled probit model here rather than the random effects models, since it is not readily apparent how to treat random effects in decompositions. In any case, as Table 3 demonstrates, results are relatively insensitive to the inclusion or exclusion of correlated random effects.

Table 4 presents the decomposition results. Controlling for personal characteristics only, most of the difference remains unexplained. Controlling for job characteristics results in considerably more of the difference being explained by differences in characteristics. Indeed, once we include detailed occupation and industry dummies, most of the gender difference is "explained". Further, when evaluated at female coefficients, the unexplained component is negative, implying that women are actually more likely to be dismissed once differences in characteristics are eliminated. 
Identifying the contributions of Specific Factors. To identify the roles of specific factors, we take Fairlie's (2006) approach. As with the modified Oaxaca-Blinder decompositions, pooled probit model estimation results rather than random effects probit results are decomposed. This approach calculates the contribution of differences in the distribution of an individual variable $x_{j}$ as equal to:

$$
\frac{1}{N_{f}} \sum_{i=1}^{N_{f}} \Phi\left(x_{i, m}^{-j^{\prime}} \hat{\beta}_{m}^{-j}+x_{i, m}^{j} \hat{\beta}_{m}^{j}\right)-\Phi\left(x_{i, m}^{-j^{\prime}} \hat{\beta}_{m}^{-j}+x_{i, f}^{j} \hat{\beta}_{m}^{j}\right)
$$

where variables are as defined in equation (1) and where each observation in the female sample is matched to an observation in the male sample. Evaluation can be undertaken at male coefficients (as in equation (2)) or at female coefficients. Noting that the male sample is larger than the female sample, this is done by first taking a random sub-sample of the male sample equal in size to the female sample. The female sample and the male sub-sample are then (separately) sorted by predicted probability of dismissal, and each member of the female sample is matched to the member of the male sub-sample with the same ranking. The drawing of the male sub-sample and calculation of equation (2) is repeated numerous times (1000 in this paper), with the mean calculated value across these replications being reported.

This method can also be applied to groups of variables rather than simply the single variable $x_{j}$. For example, the age dummies are logically considered as a group. The Fairlie approach has the attractive feature that the sum of effects of individual variables (or groups of variables) is equal to the total effect of differences in the distribution of all characteristics.

Table 5 presents results for the two specifications that include both personal and job characteristics. The table shows that the characteristics to make the biggest contribution to the difference in the dismal rate are occupation and industry. When the aggregated occupation and industry categories are employed, differences in the distributions of men and women across these categories explain between 0.82 and 1.01 percentage points of the 1.31 percentage point difference in mean predicted probability of dismissal. When the disaggregated categories are employed, this 
rises to between 1.19 and 2.77 . Clearly, the occupations and industries in which men and women work play a big part in explaining the higher rate of dismissal among male employees.

Other job characteristics and personal characteristics have either negligible or ambiguous effects, or act to increase the gap between male and female dismissal rates. In particular, differences between male and female employees in their work experience, type of employment contract and length of job tenure act to increase the gap in dismissal rates, while the roles of differences between male and female employees in the distributions of all other characteristics depend on whether evaluation is at male or female coefficients and/or are very close to zero.

\section{Conclusion}

Our findings are broadly consistent with the hypothesis that women tend to choose jobs with lower risks of dismissal. It is, however, perhaps significant that the male-female difference in the dismissal rate only becomes statistically insignificant once detailed industry and occupation controls are included in our models. Correspondingly, a significant portion of the difference remains unexplained in most of the decompositions when more aggregated industry and occupation controls are employed. A potential concern is that the disaggregated specification may 'over-control' for occupation and industry. In particular, many occupations and industries are dominated by one sex at this level of disaggregation. In the same way that it has been argued that occupational and industrial sex segregation has led to feminized industries and occupations being underpaid, it may be that feminized occupations and industries are less prone to dismissals simply because they are feminized. That is, employers may adopt 'firing cultures' based on their gender mix, which they then apply to both their male and female employees. Under this scenario, there may effectively be discrimination against male employees, but it will be a product of the propensity to fire employees based on the masculinity of the occupation or industry rather than a predisposition to fire male employees. 
This caveat notwithstanding, our results suggest that differences between men and women in preferences over risk of job loss are the main source in the difference in dismissal rates. This potentially provides an explanation for at least part of the gender wage gap. However, we have not directly investigated this question, which we leave for further research. A further question raised by our findings is why women have a stronger preference for jobs with lower dismissal probabilities. One obvious potential source is that costs of dismissal are higher for women. Investigation of gender differences in costs of dismissal, and its consequences more broadly, would therefore seem to be a useful avenue for future research.

\section{REFERENCES}

Altonji, Joseph G., and Rebecca M. Blank. 1999. "Race and Gender in the Labor Market." In Handbook of Labor Economics, Volume 3, edited by Orley C. Ashenfelter and David Card, pp. 3143-3259. Amsterdam: Elsevier.

Anker, Richard. 1998. Gender and Jobs: Sex Segregation of Occupations in the World. International Labour Organization, Washington.

Antcliff, Valerie, and Richard Saundry. 2009. "Accompaniment, Workplace Representation and Disciplinary Outcomes in British Workplaces - Just a Formality?" British Journal of Industrial Relations 47(1): 100-121.

Balchin, Jeffrey, and Mark Wooden. 1995. "Absence Penalties and Work Attendance." Australian Economic Review 28(4): 43-58.

Barrick, Murray R., Michael K. Mount, and J. Perkins Strauss. 1994. "Antecedents of Involuntary Turnover Due to a Reduction in Force." Personnel Psychology 47(3): 515-535.

Blau, Francine D., and Lawrence M. Kahn. 1981. "Causes and Consequences of Layoffs." Economic Inquiry 19(2): 270-296.

Booth, Alison L., Marco Francesconi, and Carlos Garcia-Serrano. 2000. "Job Tenure and Job Mobility in Britain." Industrial and Labor Relations Review 53(1): 43-70.

Booth, Alison L., and Marco Francesconi. 2000. "Job Mobility in the 1990s Britain: Does Gender Matter?" Research in Labor Economics 19: 173-189. 
Campbell, Carl M., III. 1997. "The Determinants of Dismissals, Quits, and Layoffs: A Multinomial Logit Approach." Southern Economic Journal 63(4): 1966-1073.

European Communities (Group of Experts on Gender, Social Inclusion and Employment). 2006. The Gender Pay Gap - Origins and Policy Responses: A Comparative Review of 30 European Countries. Luxembourg: Office for Official Publications of the European Communities.

Fairlie, Robert W. 1999. "The Absence of African-American Owned Business: An Analysis of the Dynamics of Self-Employment."Journal of Labor Economics 17(1): 80-108.

Fairlie, Robert W. 2006. "An Extension of the Blinder-Oaxaca Decomposition Technique to Logit and Probit Models." IZA Discussion Paper No. 1917. Bonn: Institute for the Study of Labor.

Freeman, Richard B. 1980. "The Effect of Unionism on Worker Attachment to Firms." Journal of Labor Research 1(1): 29-61.

Giuliano, Laura, David I. Levine, and Jonathan Leonard. 2006. "Do Race, Age, and Gender Differences Affect Manager-Employee Relations? An Analysis of Quits, Dismissals, and Promotions at a Large Retail Firm." UC Berkeley: Institute for Research on Labor and Employment. Retrieved from: http://escholarship.org/uc/item/9tc8n5j7

Goerke, Laszlo, and Markus Pannenberg. 2009. "Trade Union Membership and Dismissals." IZA Discussion Paper no. 522. Bonn: Institute for the Study of Labor.

Hagenaars, Aldi J. M., Klaas de Vos and M. Asghar Zaidi. 1994. Poverty Statistics in the Late 1980s: Research Based on Micro-data. Luxembourg: Office for Official Publications of the European Communities.

Keith, Kirsten, and McWilliams, Abigail. 1999. "The Returns to Mobility and Job Search by Gender." Industrial and Labor Relations Review 52(3): 460-477.

McGuinness, Seamus, and Mark Wooden. 2009. "Overskilling, Job Insecurity, and Career Mobility." Industrial Relations: A Journal of Economy \& Society 48(2): 265-286.

Orellano, Veronica I.F., and Paulo Picchetti. 2005. "An Analysis of Quit and Dismissal Determinants Between 1988 and 1999 Using the Bivariate Probit Model." Brazilian Review of Econometrics 25(1): 3-42.

Picot, Garnett, Zhengxi Lin, and Wendy Pyper. 1998. "Permanent Layoffs in Canada: Overview and Longitudinal Analysis." Canadian Journal of Economics 31(5): 1154-1178.

Saucier, Gerard. 1994. "Mini-markers: A Brief Version of Goldberg's Unipolar Big-five Markers." Journal of Personality Assessment 63(3): 506-516. 
Stumpf, Stephen A., and Patricia Kelly Dawley. 1981. "Predicting Voluntary and Involuntary Turnover Using Absenteeism and Performance Indices." Academy of Management Journal 24(1): 148163.

Summerfield, Michelle (ed). 2010. HILDA User Manual - Release 9. Melbourne: Melbourne Institute of Applied Economic and Social Research, University of Melbourne.

Theodossiou, I. 2002. "Factors Affecting the Job-to-Joblessness Turnover and Gender." Labour 16(4): 729-746.

Verbeek, Marno, and Theo Nijman. 1992. "Testing for Selectivity Bias in Panel Data Models." International Economic Review 33(3): 681-703.

Ware, John E., Kristin K. Snow, Mark Kosinski, and Barbara Gandek. 2000. SF-36 Health Survey: Manual and Interpretation Guide. Lincoln, RI: QualityMetric Inc.

Wells, Deborah L., and Paul M. Muchinsky. 1985. "Performance Antecedents of Voluntary and Involuntary Managerial Turnover." Journal of Applied Psychology 70(2): 329-336.

Watson, Nicole, and Mark Wooden. 2010. "The HILDA Survey Progress and Future Developments." The Australian Economic Review 43(3): 326-336.

Wooden, Mark, and Nicole Watson. 2007. "The HILDA Survey and its Contribution to Economic and Social Research (So Far)." The Economic Record 83(261): 208-231. 
FIGURE 1

Annual Rates of Dismissal From Main Job Held at Time of Annual Interview by Sex

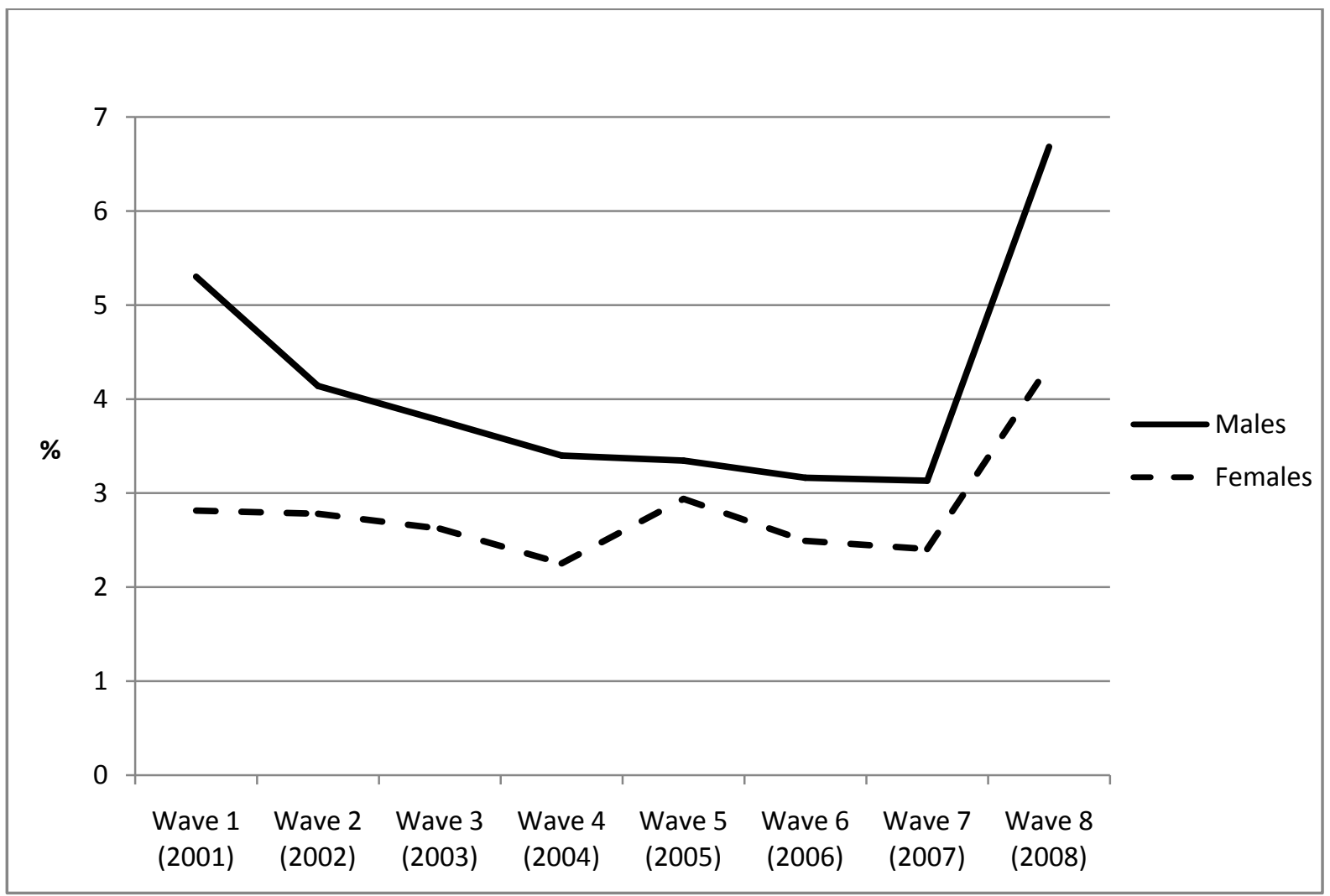


TABLE 1

Annual Rates of Job Dismissal from Main Job By SeX and Selected Characteristics:

EMPLOYEES, 2001-2009 (POOLED)

\begin{tabular}{|c|c|c|c|}
\hline & Males (\%) & Females (\%) & $\begin{array}{l}\text { Male-female } \\
\text { ratio }\end{array}$ \\
\hline \multicolumn{4}{|l|}{ Age group (years) } \\
\hline $15-24$ & 5.0 & 3.4 & 1.47 \\
\hline $25-44$ & 3.9 & 2.8 & 1.39 \\
\hline $45-54$ & 3.8 & 2.5 & 1.52 \\
\hline $55+$ & 4.1 & 2.8 & 1.46 \\
\hline \multicolumn{4}{|l|}{ Employment status } \\
\hline Part-time (usual weekly work hours <35) & 4.8 & 3.1 & 1.55 \\
\hline Full-time (usual weekly work hours $35+$ ) & 4.0 & 2.6 & 1.54 \\
\hline \multicolumn{4}{|l|}{ Type of employment contract } \\
\hline Permanent / ongoing & 3.6 & 2.4 & 1.50 \\
\hline Fixed-term & 4.4 & 2.7 & 1.63 \\
\hline Casual & 6.1 & 4.1 & 1.49 \\
\hline \multicolumn{4}{|l|}{ Firm size } \\
\hline$<20$ employees & 6.0 & 4.4 & 1.36 \\
\hline 20-99 employees & 4.7 & 3.3 & 1.42 \\
\hline $100+$ employees & 3.2 & 2.1 & 1.52 \\
\hline \multicolumn{4}{|l|}{ Sector } \\
\hline Public & 3.2 & 1.8 & 1.78 \\
\hline Private & 4.7 & 3.7 & 1.27 \\
\hline Total & 4.1 & 2.8 & 1.46 \\
\hline
\end{tabular}


TABLE 2

Mean Marginal Effects Estimates from Random Effects Probit Models of the Probability of

DISMISSAL

\begin{tabular}{|c|c|c|c|c|c|c|}
\hline & \multicolumn{2}{|c|}{ (i) } & \multicolumn{2}{|c|}{ (ii) } & \multicolumn{2}{|c|}{ (iii) } \\
\hline & Estimate & SE & Estimate & SE & Estimate & SE \\
\hline \multicolumn{7}{|l|}{ Personal characteristics } \\
\hline Male & $0.010 * *$ & 0.002 & $0.005^{* *}$ & 0.002 & 0.003 & 0.002 \\
\hline \multicolumn{7}{|l|}{ Age group ('15-24' omitted) } \\
\hline $25-34$ & -0.002 & 0.003 & -0.001 & 0.003 & -0.001 & 0.003 \\
\hline $35-44$ & 0.000 & 0.003 & 0.004 & 0.003 & 0.004 & 0.004 \\
\hline $45-54$ & 0.001 & 0.003 & $0.009 * *$ & 0.003 & $0.008 * *$ & 0.004 \\
\hline 55 or over & 0.005 & 0.003 & $0.015^{* *}$ & 0.004 & $0.015^{* *}$ & 0.004 \\
\hline \multicolumn{7}{|c|}{ Educational attainment ('No post-school qualifications' omitted) } \\
\hline Degree & $-0.013 * *$ & 0.002 & -0.004 & 0.003 & -0.003 & 0.003 \\
\hline Other post-school qualification & $-0.004 * *$ & 0.002 & -0.002 & 0.002 & -0.002 & 0.002 \\
\hline Disabled & $0.004 *$ & 0.002 & $0.005^{* *}$ & 0.002 & $0.005^{* *}$ & 0.002 \\
\hline General health (SF-36) & $-1.34 \mathrm{E}-04^{* *}$ & 4.15E-05 & $-1.57 \mathrm{E}-04 * *$ & 4.63E-05 & $-1.53 \mathrm{E}-04^{* *}$ & $4.66 \mathrm{E}-05$ \\
\hline Health missing & -0.003 & 0.004 & -0.005 & 0.004 & -0.005 & 0.004 \\
\hline Extroversion & $0.002 * *$ & 0.001 & $0.002 * *$ & 0.001 & $0.002^{* *}$ & 0.001 \\
\hline Agreeableness & -0.001 & 0.001 & 0.000 & 0.001 & 0.000 & 0.001 \\
\hline Conscientiousness & $-0.002^{* *}$ & 0.001 & $-0.002 * *$ & 0.001 & $-0.002^{* *}$ & 0.001 \\
\hline Emotional stability & -0.001 & 0.001 & 0.000 & 0.001 & 0.000 & 0.001 \\
\hline Openness to experience & $0.002^{*}$ & 0.001 & 0.001 & 0.001 & 0.001 & 0.001 \\
\hline Personality measures missing & -0.004 & 0.007 & -0.001 & 0.008 & -0.001 & 0.008 \\
\hline \multicolumn{7}{|c|}{ Immigrant and indigenous status ('Non-indigenous Australian-born' omitted) } \\
\hline ESB immigrant & $0.007^{* *}$ & 0.002 & $0.006 * *$ & 0.003 & $0.005^{* *}$ & 0.003 \\
\hline Indigenous or NESB immigrant & $0.006^{* *}$ & 0.002 & $0.004^{*}$ & 0.002 & 0.004 & 0.002 \\
\hline Household equivalized income $\left(\$^{\prime} 000\right)$ & $-2.96 \mathrm{E}-05$ & 2.93E-05 & $-1.02 \mathrm{E}-05$ & 3.36E-05 & $-2.53 \mathrm{E}-05$ & $3.41 \mathrm{E}-05$ \\
\hline \multicolumn{7}{|l|}{ Years of work experience ('<5' omitted) } \\
\hline $5-<10$ & 0.000 & 0.003 & 0.001 & 0.003 & 0.001 & 0.003 \\
\hline $10-<20$ & $-0.007 * *$ & 0.003 & -0.005 & 0.003 & -0.005 & 0.003 \\
\hline $20-<30$ & $-0.010 * *$ & 0.003 & -0.005 & 0.004 & -0.005 & 0.004 \\
\hline $30+$ & $-0.011 * *$ & 0.003 & $-0.008 * *$ & 0.003 & $-0.008 * *$ & 0.003 \\
\hline Experience missing & $0.018^{* *}$ & 0.004 & $0.011 * *$ & 0.004 & $0.011^{* *}$ & 0.004 \\
\hline \multicolumn{7}{|l|}{ Job-related characteristics } \\
\hline Union member & & & 0.000 & 0.002 & 0.002 & 0.002 \\
\hline Job tenure (years) & & & $-0.003 * *$ & 0.0003 & $-0.003^{* *}$ & 0.0003 \\
\hline Job tenure squared / 100 & & & $0.008 * *$ & 0.001 & $0.008^{* *}$ & 0.001 \\
\hline Part-time & & & 0.000 & 0.002 & 0.002 & 0.002 \\
\hline \multicolumn{7}{|c|}{ Employment contract ('Permanent/ongoing' omitted) } \\
\hline Fixed term & & & 0.004 & 0.003 & $0.005^{*}$ & 0.003 \\
\hline Casual & & & $0.009 * *$ & 0.002 & $0.010 * *$ & 0.002 \\
\hline Private sector & & & $0.013^{* *}$ & 0.003 & $0.013^{* *}$ & 0.003 \\
\hline \multicolumn{7}{|l|}{ Firm size (' $100+$ employees' omitted) } \\
\hline Fewer than 20 employees & & & $0.009 * *$ & 0.002 & $0.008^{* *}$ & 0.002 \\
\hline 20-99 employees & & & $0.006 * *$ & 0.002 & $0.005^{* *}$ & 0.002 \\
\hline Firm size missing & & & $0.012^{* *}$ & 0.004 & $0.012 * *$ & 0.004 \\
\hline Work on weekends & & & -0.002 & 0.002 & -0.001 & 0.002 \\
\hline Work nights or irregular hours & & & $-0.005^{* *}$ & 0.002 & $-0.004^{*}$ & 0.002 \\
\hline Log hourly wage & & & $0.005^{* *}$ & 0.002 & $0.004^{* *}$ & 0.002 \\
\hline \multicolumn{7}{|l|}{ Occupation ('Manager' omitted) } \\
\hline Professional & & & $-0.010^{* *}$ & 0.003 & \multicolumn{2}{|c|}{ Contains 40} \\
\hline
\end{tabular}


Technician / trade

Community and personal service

Clerical and administrative

Sales

Machinery operator / driver

Laborer

Industry ('Agriculture, mining'

omitted)

Manufacturing

Construction

Wholesale and retail trade

Hospitality

Transport, communication

Professional services

Government, education, health

Arts, recreation and other services

Other factors

Local unemployment rate

Wave 2

Wave 3

Wave 4

Wave 5

Wave 6

Wave 7

Wave 8

Number of observations

Log likelihood

$\operatorname{LR}(\rho=0)$

$\begin{array}{ll}-0.004 & 0.003 \\ -0.003 & 0.004 \\ -0.005^{*} & 0.003 \\ -0.006^{*} & 0.004 \\ -0.003 & 0.004 \\ -0.003 & 0.003\end{array}$

$0.010 * * \quad 0.004$

$0.012 * * \quad 0.004$

$-0.006 \quad 0.004$

$0.001 \quad 0.004$

$0.005 \quad 0.004$

$0.003 \quad 0.004$

$-0.021 * * \quad 0.004$

$0.000 \quad 0.005$

$\begin{array}{llll}0.000 & 0.0007 & -0.001 & 0.001\end{array}$

$-0.006 * \quad 0.003$

0.003
0.004

$0.000 \quad 0.001$

$-0.005 * \quad 0.0026$

$-0.008 * * \quad 0.0028$

$-0.008 * * \quad 0.003$

$-0.021 * *$

$-0.021 * * \quad 0.004$

$-0.005 * \quad 0.003$

$-0.020 * * \quad 0.004$

$-0.010 * * \quad 0.003$

$-0.022^{* *}$

0.004

$-0.020 * * \quad 0.005$

$-0.012 * * \quad 0.0033$

$-0.013 * * \quad 0.0033$

$-0.025 * *$

0.005

$-0.021^{* *} \quad 0.005$

$-0.024 * * \quad 0.005$

$-0.026 * * \quad 0.005$

0.005

0.0031

$-0.006$

0.005

$-0.005$

0.005

NOTES: SE - Standard error. $\rho$ - Proportion of the total variance contributed by the panel-level variance component. $L R(\rho=$ $0)$ - Likelihood-ratio test for $\rho$ equal to zero (distributed as $\chi^{2}(1)$ under the null hypothesis-critical value at the 95 per cent level is 3.84$){ }^{*}$ and ${ }^{* *}$ indicate statistical significance at the 10 and 5 per cent levels, respectively. 
TABLE 3

Sensitivity Analysis: Mean Marginal Effect Estimates for the 'Male' Dummy

\begin{tabular}{|c|c|c|c|c|c|c|}
\hline & \multicolumn{2}{|c|}{ (i) } & \multicolumn{2}{|c|}{ (ii) } & \multicolumn{2}{|c|}{ (iii) } \\
\hline & Estimate & SE & Estimate & SE & Estimate & SE \\
\hline Main specification & $0.010 * *$ & 0.0016 & $0.005^{* *}$ & 0.0020 & 0.003 & 0.0021 \\
\hline Broad definition of dismissal & $0.009 * *$ & 0.0018 & $0.006 * *$ & 0.0023 & 0.003 & 0.0024 \\
\hline $\begin{array}{l}\text { Employees with strong labour } \\
\text { market attachment only }\end{array}$ & $0.011^{* *}$ & 0.0021 & $0.005^{*}$ & 0.0025 & 0.003 & 0.0027 \\
\hline Excluding employees who quit & $0.011 * *$ & 0.0017 & $0.005^{* *}$ & 0.0022 & 0.003 & 0.0023 \\
\hline $\begin{array}{l}\text { Allowing for attrition bias - } \\
\text { Number of waves responded }\end{array}$ & $0.010 * *$ & 0.0016 & $0.005^{* *}$ & 0.0020 & 0.003 & 0.0021 \\
\hline $\begin{array}{l}\text { Allowing for attrition bias - } \\
\text { Proportion of in-scope waves } \\
\text { responded }\end{array}$ & $0.010 * *$ & 0.0016 & $0.005^{* *}$ & 0.0020 & 0.003 & 0.0021 \\
\hline Pooled probit & $0.013^{* *}$ & 0.0018 & $0.005^{* *}$ & 0.0021 & 0.003 & 0.0022 \\
\hline
\end{tabular}

NOTES: SE - Standard error. * and ** indicate statistical significance at the 10 and 5 per cent levels, respectively..

TABLE 4

Blinder-OAXaca Decompositions of SeX Differences in the Probability of Job Loss (\%)

Evaluated at:

Male coefficients Female coefficients

Personal characteristics only

Due to differences in characteristics

$0.10 \quad 0.00$

Unexplained

$1.20 \quad 1.30$

Personal and job characteristics

Due to differences in characteristics

1.00

0.60

Unexplained

0.30

0.70

Personal and job characteristics, with disaggregated occupation and industry groups
Due to differences in characteristics
1.21
2.24
Unexplained
0.25
$-0.77$

NOTE: Total difference in the mean predicted probability of job loss is 1.31 percentage points. 
TABLE 5

Contributions of Components of Characteristics to the Male-Female Difference in the Probability OF JOB LOSS: FAIRLIE DECOMPOSITIONS

\begin{tabular}{|c|c|c|c|c|c|c|c|c|}
\hline & \multicolumn{4}{|c|}{$\begin{array}{l}\text { Aggregated occupation } \\
\text { and industry groups }\end{array}$} & \multicolumn{4}{|c|}{$\begin{array}{l}\text { Disaggregated occupation } \\
\text { and industry groups }\end{array}$} \\
\hline & \multicolumn{2}{|c|}{$\begin{array}{l}\text { Evaluated at female } \\
\text { coefficients }\end{array}$} & \multicolumn{2}{|c|}{$\begin{array}{l}\text { Evaluated at male } \\
\text { coefficients }\end{array}$} & \multicolumn{2}{|c|}{$\begin{array}{c}\text { Evaluated at } \\
\text { female coefficients }\end{array}$} & \multicolumn{2}{|c|}{$\begin{array}{c}\text { Evaluated at male } \\
\text { coefficients }\end{array}$} \\
\hline Total difference & \multicolumn{2}{|c|}{-1.310} & \multicolumn{2}{|c|}{-1.310} & \multicolumn{2}{|c|}{-1.310} & \multicolumn{2}{|c|}{-1.310} \\
\hline \multirow[t]{2}{*}{$\begin{array}{l}\text { Difference explained by } \\
\text { characteristics }\end{array}$} & \multicolumn{2}{|c|}{-0.600} & \multicolumn{2}{|c|}{-1.080} & \multicolumn{2}{|c|}{-2.170} & \multicolumn{2}{|c|}{-1.120} \\
\hline & Estimate & SE & Estimate & SE & Estimate & SE & Estimate & SE \\
\hline Age & 0.008 & 0.039 & 0.000 & 0.036 & 0.021 & 0.042 & -0.005 & 0.036 \\
\hline Education & 0.003 & 0.029 & 0.008 & 0.033 & -0.002 & 0.047 & 0.017 & 0.031 \\
\hline Health & -0.032 & 0.020 & -0.006 & 0.012 & 0.012 & 0.025 & -0.006 & 0.012 \\
\hline Personality & 0.012 & 0.084 & -0.019 & 0.081 & 0.030 & 0.098 & -0.022 & 0.081 \\
\hline Indigenous and immigrant status & -0.004 & 0.011 & -0.001 & 0.010 & 0.001 & 0.014 & -0.003 & 0.010 \\
\hline Household income & 0.000 & 0.005 & 0.001 & 0.009 & 0.004 & 0.013 & 0.005 & 0.010 \\
\hline Work experience & 0.024 & 0.038 & 0.030 & 0.042 & 0.039 & 0.041 & 0.025 & 0.043 \\
\hline Union membership & 0.021 & 0.015 & -0.008 & 0.014 & 0.028 & 0.035 & -0.020 & 0.017 \\
\hline Job tenure & $0.080^{* *}$ & 0.038 & $0.077^{* *}$ & 0.038 & $0.185^{* *}$ & 0.063 & 0.050 & 0.041 \\
\hline Part-time / full-time status & 0.011 & 0.097 & -0.108 & 0.129 & 0.043 & 0.127 & 0.016 & 0.139 \\
\hline Type of employment contract & $0.103 * *$ & 0.046 & $0.141 * *$ & 0.054 & $0.165^{* *}$ & 0.072 & $0.167^{* *}$ & 0.060 \\
\hline Sector & -0.013 & 0.013 & 0.006 & 0.015 & -0.007 & 0.009 & 0.009 & 0.014 \\
\hline Firm size & -0.011 & 0.018 & 0.000 & 0.015 & 0.039 & 0.031 & 0.011 & 0.015 \\
\hline Weekend shifts & 0.005 & 0.009 & 0.001 & 0.006 & 0.003 & 0.008 & 0.000 & 0.007 \\
\hline Night shifts & -0.008 & 0.010 & -0.010 & 0.010 & -0.011 & 0.012 & -0.006 & 0.010 \\
\hline Wage (log hourly wage) & 0.023 & 0.031 & $-0.182 * *$ & 0.046 & 0.046 & 0.051 & $-0.172 * *$ & 0.048 \\
\hline Occupation & -0.099 & 0.189 & -0.189 & 0.135 & $-1.675^{* *}$ & 0.680 & $-0.490 * *$ & 0.225 \\
\hline Industry & $-0.717 * *$ & 0.163 & $-0.823 * *$ & 0.115 & $-1.092^{* *}$ & 0.271 & $-0.698 * *$ & 0.217 \\
\hline
\end{tabular}

NOTES: SE - Standard error. * and ** indicate statistical significance at the 10 and 5 per cent levels, respectively. 


\section{Appendix: Variable Means —Pooled Data}

\begin{tabular}{|c|c|c|c|c|c|}
\hline Variable & Males & Females & Variable & Males & Females \\
\hline Dismissed & 0.041 & 0.028 & Dismissed - broad definition & 0.053 & 0.041 \\
\hline Aged 15-24 & 0.210 & 0.210 & Extroversion & 3.90 & 4.25 \\
\hline Aged 25-34 & 0.231 & 0.208 & Agreeableness & 4.61 & 5.17 \\
\hline Aged 35-44 & 0.250 & 0.252 & Conscientiousness & 4.49 & 4.81 \\
\hline Aged 45-54 & 0.202 & 0.230 & Emotional stability & 4.61 & 4.77 \\
\hline Aged 55 or over & 0.107 & 0.100 & Openness to experience & 3.85 & 3.88 \\
\hline Degree & 0.228 & 0.283 & Personality measures missing & 0.098 & 0.077 \\
\hline Other post-school qualification & 0.339 & 0.228 & Years of work experience: $0-<5$ & 0.185 & 0.201 \\
\hline Disabled & 0.148 & 0.144 & Years of work experience: $5-<10$ & 0.113 & 0.127 \\
\hline General health (SF-36 measure) & 65.1 & 67.1 & Years of work experience: $10-<20$ & 0.222 & 0.276 \\
\hline Health missing & 0.101 & 0.080 & Years of work experience: $20-<30$ & 0.231 & 0.231 \\
\hline ESB immigrant & 0.095 & 0.086 & Years of work experience: $30+$ & 0.294 & 0.220 \\
\hline NESB immigrant & 0.112 & 0.120 & Years of work experience missing & 0.033 & 0.031 \\
\hline Real h'hold equivalized income $(\$ 000)$ & 44.70 & 44.45 & & & \\
\hline Union member & 0.293 & 0.276 & Firm size: Fewer than 20 employees & 0.218 & 0.213 \\
\hline Job tenure (years) & 6.47 & 5.51 & Firm size: 20-99 employees & 0.163 & 0.144 \\
\hline Job tenure squared / 100 & 1.07 & 0.76 & Firm size: 100 or more employees & 0.594 & 0.604 \\
\hline Part-time & 0.166 & 0.489 & Firm size missing & 0.026 & 0.038 \\
\hline Fixed term & 0.091 & 0.093 & Work on weekends & 0.285 & 0.247 \\
\hline Casual & 0.186 & 0.285 & Work nights or irregular hours & 0.252 & 0.252 \\
\hline \multirow[t]{2}{*}{ Private sector } & 0.594 & 0.532 & Log hourly wage & 3.10 & 2.98 \\
\hline & & & Local unemployment rate & 5.03 & 5.01 \\
\hline Occupation (aggregated) & & & Industry (aggregated) & & \\
\hline Manager & 0.124 & 0.070 & Agriculture, mining & 0.079 & 0.017 \\
\hline Professional & 0.201 & 0.274 & Manufacturing & 0.155 & 0.053 \\
\hline Technician / trade & 0.210 & 0.039 & Construction & 0.090 & 0.012 \\
\hline Community and personal service & 0.067 & 0.152 & Wholesale and retail trade & 0.135 & 0.150 \\
\hline Clerical and administrative & 0.085 & 0.239 & Hospitality & 0.056 & 0.082 \\
\hline Sales & 0.071 & 0.137 & Transport, communication & 0.094 & 0.045 \\
\hline Machinery operator / driver & 0.112 & 0.010 & Professional services & 0.123 & 0.150 \\
\hline \multirow[t]{2}{*}{ Laborer } & 0.130 & 0.078 & Government, education, health & 0.209 & 0.447 \\
\hline & & & Arts, recreation and other services & 0.060 & 0.044 \\
\hline Occupation (disaggregated) & & & Industry (disaggregated) & & \\
\hline Other manager & 0.092 & 0.043 & Agriculture, fishing and forestry & 0.032 & 0.010 \\
\hline Hospitality, retail or service manager & 0.032 & 0.027 & Mining & 0.029 & 0.004 \\
\hline Business professional & 0.061 & 0.055 & Food, beverage and tobacco manuf. & 0.028 & 0.018 \\
\hline Design, engineering, etc. professional & 0.039 & 0.015 & Textile, leather, clothing, etc. manuf. & 0.011 & 0.007 \\
\hline Education professional & 0.041 & 0.101 & Pulp, paper and printing & 0.013 & 0.005 \\
\hline Health professional & 0.015 & 0.073 & Mineral, chemical, polymer, etc. manuf. & 0.024 & 0.007 \\
\hline ICT professional & 0.030 & 0.006 & Metal products manufacturing & 0.027 & 0.004 \\
\hline Legal, social or welfare professional & 0.015 & 0.024 & Transport equipment manufacturing & 0.022 & 0.003 \\
\hline Engineering, ICT or science technician & 0.032 & 0.010 & Machinery and equipment manuf. & 0.021 & 0.005 \\
\hline Auto or engineering trades worker & 0.063 & 0.001 & Furniture and other manufacturing & 0.008 & 0.003 \\
\hline Construction trades worker & 0.029 & 0.000 & Utilities and waste collection & 0.018 & 0.004 \\
\hline Telecommunications trades worker & 0.034 & 0.000 & Building construction & 0.029 & 0.005 \\
\hline Food trades worker & 0.017 & 0.008 & Heavy and civil engineering constr. & 0.012 & 0.002 \\
\hline Skilled animal or horticultural worker & 0.016 & 0.005 & Construction services & 0.049 & 0.005 \\
\hline Other technicians or trades worker & 0.019 & 0.014 & Basic material wholesaling & 0.011 & 0.003 \\
\hline Health and welfare support workers & 0.007 & 0.022 & Machinery and equipment wholesaling & 0.010 & 0.005 \\
\hline
\end{tabular}




\begin{tabular}{|c|c|c|c|c|c|}
\hline Carer or aide & 0.010 & 0.075 & Motor vehicles and parts wholesaling & 0.005 & 0.001 \\
\hline Hospitality worker & 0.015 & 0.037 & Grocery, liquor and tobacco production & 0.008 & 0.005 \\
\hline Protective service worker & 0.027 & 0.007 & Other wholesaling & 0.009 & 0.008 \\
\hline Sports pr personal service worker & 0.008 & 0.011 & Motor vehicle and parts retailing & 0.013 & 0.003 \\
\hline Office manager or program admin. & 0.013 & 0.031 & Fuel and food retailing & 0.035 & 0.045 \\
\hline Personal assistant or secretary & 0.000 & 0.029 & Other retailing & 0.043 & 0.079 \\
\hline General clerical workers & 0.009 & 0.048 & Accommodation & 0.009 & 0.014 \\
\hline Inquiry clerk or receptionist & 0.008 & 0.048 & Food and beverage services & 0.047 & 0.068 \\
\hline Numerical clerk & 0.014 & 0.052 & Transport & 0.038 & 0.009 \\
\hline Clerical or office support worker & 0.011 & 0.009 & Postal and courier pick-up and delivery & 0.010 & 0.006 \\
\hline Other clerical or administrative & 0.030 & 0.023 & Transport support \& warehousing & 0.018 & 0.005 \\
\hline Sales representative or agents & 0.017 & 0.012 & Publishing and broadcasting & 0.009 & 0.013 \\
\hline Sales Assistant or salesperson & 0.044 & 0.094 & Telecommunications and internet & 0.018 & 0.008 \\
\hline Sales support worker & 0.009 & 0.031 & Library and other information services & 0.002 & 0.004 \\
\hline Machine or stationary plant operator & 0.031 & 0.005 & Finance & 0.014 & 0.023 \\
\hline Mobile plant operator & 0.022 & 0.001 & Insurance and superannuation funds & 0.006 & 0.010 \\
\hline Road or rail driver & 0.044 & 0.003 & Auxiliary finance and insurance services & 0.011 & 0.010 \\
\hline Storeperson & 0.015 & 0.002 & Rental services and property operators & 0.011 & 0.015 \\
\hline Cleaner or laundry worker & 0.015 & 0.028 & Professional, scientific \& technical & 0.044 & 0.058 \\
\hline Construction or mining laborer & 0.022 & 0.000 & Computer system design and related & 0.019 & 0.006 \\
\hline Factory process worker & 0.030 & 0.018 & Administrative services & 0.011 & 0.018 \\
\hline Farm, forestry or garden worker & 0.016 & 0.005 & Building cleaning, pest control, etc. & 0.007 & 0.009 \\
\hline Food preparation assistant & 0.016 & 0.016 & Public administration & 0.053 & 0.049 \\
\hline \multirow[t]{13}{*}{ Other laborer } & 0.031 & 0.011 & Defence & 0.014 & 0.003 \\
\hline & & & Public order, safety and regulatory & 0.029 & 0.011 \\
\hline & & & Preschool and school education & 0.040 & 0.124 \\
\hline & & & Tertiary education & 0.022 & 0.029 \\
\hline & & & Adult, community and other education & 0.005 & 0.009 \\
\hline & & & Hospitals & 0.017 & 0.070 \\
\hline & & & Medical and other health care services & 0.011 & 0.055 \\
\hline & & & Residential care services & 0.007 & 0.041 \\
\hline & & & Social assistance services & 0.012 & 0.055 \\
\hline & & & Heritage $\&$ creative $\&$ performing arts & 0.005 & 0.005 \\
\hline & & & Sports, recreation \& gambling activities & 0.016 & 0.011 \\
\hline & & & Repair and maintenance & 0.028 & 0.003 \\
\hline & & & Personal and other services & 0.011 & 0.025 \\
\hline
\end{tabular}

NOTE: ESB denotes English-speaking-background and NESB denotes non-English-speaking background. 


\section{ENDNOTES}

${ }^{1}$ Another response option is 'Job was temporary or seasonal', which could, in some cases, be interpreted as termination of employment initiated by the employer. However, employees will typically take these jobs knowing that they are short-term, and in some cases, and possibly most, will only desire short-term employment. We, therefore, exclude this response option from our definition of job dismissal in our main analysis. We do, however, subsequently test how robust our findings are to changes in the definition.

${ }^{2}$ Blau and Kahn (1981) also acknowledge that tenure may, in part, capture an unobserved individual fixed effect, with those less prone to dismissal tending to have longer tenures.

${ }^{3} \mathrm{~A}$ list of all the variables used in this analysis, together with their mean values, is provided in an Appendix.

${ }^{4}$ The data itself suggest this is a reasonable assumption, with rank order correlations over the two periods varying from 0.59 for the agreeableness scale up to 0.73 for extroversion.

${ }^{5}$ Occupation is coded using the Australian and New Zealand Standard Classification of Occupation system (ANZSCO), First Edition, 2006 (ABS cat. no. 1220.0), while industry is coded using the Australian and New Zealand Standard Industrial Classification (ANZSIC), Second Edition, 2006 (ABS cat. no.1292.0). The broad groups are based on the 'one-digit' (most aggregated) categories in these classification schemes, and the detailed groups are based on the 'two-digit' (next-most aggregated) categories.

${ }^{6}$ Full model results are available on request, from the authors.

${ }^{7}$ Evaluated at female coefficients, the right-hand sides of equation (1) becomes:

$\left[1 / N_{m} \sum_{i=1}^{N_{m}} \Phi\left(x_{i, m}^{i} \hat{\beta}_{f}\right)-1 / N_{f} \sum_{i=1}^{N_{f}} \Phi\left(x_{i, f}^{i} \hat{\beta}_{f}\right)\right]+\left[1 / N_{f} \sum_{i=1}^{N_{f}} \Phi\left(x_{i, m}^{i} \hat{\beta}_{m}\right)-1 / N_{f} \sum_{i=1}^{N_{f}} \Phi\left(x_{i, m} \hat{\beta}_{f}\right)\right]$ 